9. Aubry M, Finke J, Teissier A, Roche C, Broult J, Paulous S, et al. Silent circulation of Ross River virus in French Polynesia. Int J Infect Dis. 2015;37:19-24. http://dx.doi.org/10.1016/ j.ijid.2015.06.005

10. Stephenson EB, Peel AJ, Reid SA, Jansen CC, McCallum H. The non-human reservoirs of Ross River virus: a systematic review of the evidence. Parasit Vectors. 2018;11:188. http://dx.doi.org/10.1186/s13071-018-2733-8

Address for correspondence: Van-Mai Cao-Lormeau, Institut Louis Malardé, PO Box 30, 98713 Papeete, Tahiti, French Polynesia; email: mlormeau@ilm.pf

\title{
Malignant Aspergillus flavus Otitis Externa with Jugular Thrombosis
}

\section{Maxime Moniot, Marion Montava, Stéphane Ranque, Ugo Scemama, Carole Cassagne, Varoquaux Arthur}

\author{
Author affiliations: Aix-Marseille University, Marseille, France \\ (M. Moniot, S. Ranque, C. Cassagne); La Conception University \\ Hospital, Marseille (M. Montava, U. Scemama, V. Arthur) \\ DOI: https://doi.org/10.3201/eid2504.180710
}

We report a case of malignant otitis externa with jugular vein thrombosis caused by Aspergillus flavus. Magnetic resonance imaging revealed an unusual ink smudge pattern deep in a cervical abscess. The pattern was consistent with mycetoma and may be important for diagnosing these life-threatening infections.

A 73-year-old male patient sought care from the otorhinolaryngology department at University Hospital, Marseille, France. He had a 5-month history of malignant otitis externa (MOE), which was worsening despite 4 months of treatment with intravenous ceftazidime, oral ciprofloxacin, and topical neomycin, polymyxin $\mathrm{B}$, dexamethasone, and thiomersal combination. The patient had a history of high blood pressure, treated with perindopril and nicardipine, and diabetes mellitus, inadequately controlled (hemoglobin A1c 7.7\%) with metformin and sitagliptin.

The patient was admitted, and otoscopic examination found otorrhea, inflammation, and stenosis of the right external auditory canal; we could not see the tympanic membrane. Examination of the cranial nerve was normal. Pure-tone audiogram showed a right mixed hearing loss with air-bone gap at $15 \mathrm{~dB}$ and symmetric bone curve by presbycusis. Laboratory testing showed elevated erythrocyte sedimentation level (42 $\mathrm{mm}$ at $1 \mathrm{~h}, 82 \mathrm{~mm}$ at $2 \mathrm{~h}$ ) and leukocytosis $(11 \mathrm{~g} / \mathrm{L})$; C-reactive protein results were within reference range. A computed tomography (CT) scan of the head showed thickening of the ear skin; focal tympanal bone osteolysis; partial right mastoid air cells and middleear cavity opacification; and osteolysis of the occipital, styloid, and mastoid bones consistent with MOE (Appendix Figure, https://wwwnc.cdc.gov/EID/article/25/4/18-0710App1.pdf). Magnetic resonance imaging (MRI) with contrast media confirmed skull base osteomyelitis, evidenced by bone lysis and marrow enhancement of the clivus (Figure, panels A-C). Both MRI and CT showed a right jugular vein thrombosis and cellulitis and abscess in the carotid and perivertebral spaces. Abscess content had an unusual aspect: T2-weighted imaging signal void foci surrounded by a hypersignal rim.

We treated the right jugular vein thrombosis with enoxaparin. The patient underwent surgical debridement with facial nerve monitoring; we collected transmastoid biopsy samples and pus for microbiological analysis and inserted a transtympanic aerator. Direct microscopic examination of the samples showed hyaline septate hyphae consistent with hyalohyphomycosis. Biopsy samples grew 2 bacteria, Corynebacterium striatum and Enterococcus faecalis, and 1 filamentous fungus, Aspergillus flavus, that we identified by matrix-assisted laser desorption/ionization time-of-flight mass spectrometry (Microflex LT, https:// www.bruker.com) against an in-house database described by Normand et al. (1). Etest antifungal susceptibility testing (bioMérieux, https://www.biomerieux.com) showed that the A. flavus strain was sensitive to voriconazole (MIC $0.380 \mathrm{mg} / \mathrm{L}$ ) and resistant to amphotericin B (MIC $12 \mathrm{mg} / \mathrm{L}$ ). We stopped administration of auricular drops, continued intravenous ceftazidime $(1.5 \mathrm{~g} / \mathrm{d})$ and oral ciprofloxacin $(1.5 \mathrm{~g} / \mathrm{d})$, and started voriconazole therapy (6 $\mathrm{mg} / \mathrm{kg} / 12 \mathrm{~h}$ intravenously, followed by $400 \mathrm{mg} / \mathrm{d}$ orally). Otalgia, otorrhea, and inflammatory external auditory canal symptoms were relieved, and the patient recovered after 6 weeks. No further follow-up was available.

Fungi cause $\approx 10 \%$ of MOE (2). The 3 leading species, by decreasing frequency, are A. fumigatus, A. flavus, and A. niger (3). A. flavus is more frequently involved in $\mathrm{MOE}$ than is $A$. niger $(3,4)$.

Jugular vein thrombosis (JVT) was previously reported in MOE (5) and other conditions such as Lemierre syndrome, invasive fungal infection, or any inflammatory process including otitis media. Various pathogens can cause JVT, especially Fusobacterium necrophorum and zygomycetes. 


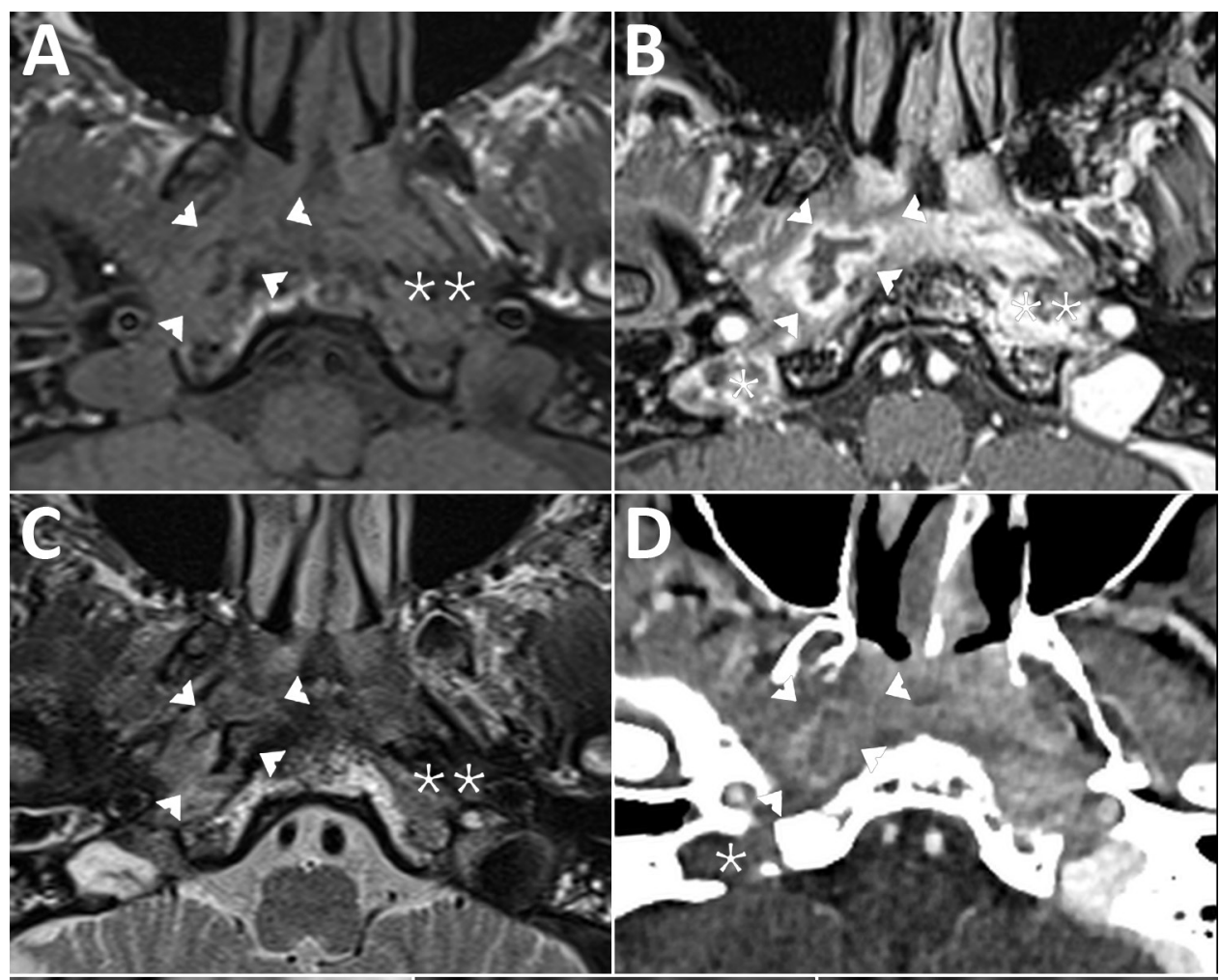

Figure. Magnetic resonance imaging (MRI) of a patient with malignant otitis externa, France. Cross-sectional imaging demonstrates a central skull base osteomyelitis in patient's temporal bone. A) T1-weighted imaging; B, E) 3-dimensional T1-weighted imaging with gadolinium enhancement and fat saturation; C, F, G) T2weighted imaging; and CT with iodine enhancement (D). Single asterisks $\left(^{*}\right)$ indicate jugular bulb thrombosis (panels B, D); double asterisks $\left(^{* *}\right)$ indicate deep-spaces cellulitis (panels $A-C)$. Arrowheads indicate parapharyngeal abscess at right (panels A-D); parapharyngeal abscess is also visible as a gray layer (panels E, G). The content of the abscess has an unusual "ink smudge" pattern with no signal in T2-weighted imaging, visible as a black layer (panels $F, G$ ). This pattern is consistent - with a mycetoma surrounded by 20.
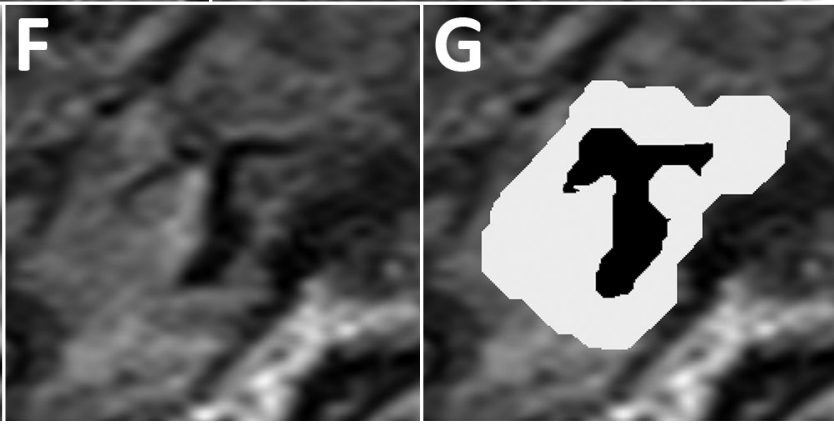
granulation tissue.

Data on JVT in MOE are scarce; we could find no previously reported case of JVT related to A. flavus MOE. Postcontrast CT with soft tissue algorithm is considered the first-line imaging modality to diagnose JVT (5). In our case, both CT and MRI confirmed the diagnosis.

Osteomyelitis and abscess showed on MRI but were hardly visible on CT (Appendix Figure). High-signal T2weighted imaging is typical in purulent content of abscesses (ด). In contrast, this case exhibited an unusual lack of T2-weighted imaging signal. This characteristic pattern is known in various mycetoma locations as paranasal fungus balls (7) or maduromycosis, for which the T2-weighted imaging dot-in-circle sign is specific (8). Most authors explain the signal void as a magnetic susceptibility behavior on T2-weighted imaging resulting from accumulation of iron and other magnetic atoms (9). This case introduced a new T2-weighted imaging signal void pattern we refer to as an "ink smudge" appearance. A bone sequestrum is a differential diagnosis, yet this lesion lacked calcification in CT. We hypothesize that the ink-smudge sign we identified could be specific to fungal infection. This report should prompt careful assessment by MRI of deep-space abscess in patients with MOE.

The standard treatment for fungal MOE is a combination of surgical debridement, systemic antifungal therapy, and control of concurrent conditions. There is no consensus for the duration of the antifungal treatment; patients usually receive 6-8 weeks of antifungal therapy, more if clinical examination or imaging follow-up supports extending treatment (10).

We highlight the potential use of an MRI ink-smudge pattern to identify fungal infection in MOE. Furthermore, because we saw JVT on both postcontrast CT and MRI scans, our findings and these images may be crucial for improving patient prognosis through timely and adequate treatment. 


\section{About the Author}

Dr. Moniot is a resident at the University Hospital Institute Méditerranée Infection, Marseille, France. His research interests include identification and diagnosis of fungal pathogens and investigation of fungal epidemiology.

\section{References}

1. Normand A-C, Cassagne C, Gautier M, Becker P, Ranque S, Hendrickx M, et al. Decision criteria for MALDI-TOF MS-based identification of filamentous fungi using commercial and in-house reference databases. BMC Microbiol. 2017;17:25. http://dx.doi.org/ 10.1186/s12866-017-0937-2

2. Bhandary S, Karki P, Sinha BK. Malignant otitis externa: a review. Pac Health Dialog. 2002;9:64-7.

3. Parize P, Chandesris M-O, Lanternier F, Poirée S, Viard J-P, Bienvenu B, et al. Antifungal therapy of Aspergillus invasive otitis externa: efficacy of voriconazole and review. Antimicrob Agents Chemother. 2009;53:1048-53. http://dx.doi.org/10.1128/ AAC.01220-08

4. Gabrielli E, Fothergill AW, Brescini L, Sutton DA, Marchionni E, Orsetti E, et al. Osteomyelitis caused by Aspergillus species: a review of 310 reported cases. Clin Microbiol Infect. 2014;20: 559-65. http://dx.doi.org/10.1111/1469-0691.12389

5. Nawas MT, Daruwalla VJ, Spirer D, Micco AG, Nemeth AJ. Complicated necrotizing otitis externa. Am J Otolaryngol. 2013;34:706-9. http://dx.doi.org/10.1016/j.amjoto.2013.07.003

6. Matt BH, Lusk RP. Delineation of a deep neck abscess with magnetic resonance imaging. Ann Otol Rhinol Laryngol. 1987;96: 615-7. http://dx.doi.org/10.1177/000348948709600526

7. Aribandi M, McCoy VA, Bazan C III. Imaging features of invasive and noninvasive fungal sinusitis: a review. Radiographics. 2007;27:1283-96. http://dx.doi.org/10.1148/rg.275065189

8. Jain V, Makwana GE, Bahri N, Mathur MK. The "dot in circle" sign on MRI in maduramycosis: a characteristic finding. J Clin Imaging Sci. 2012;2:66-66. http://dx.doi.org/10.4103/ 2156-7514.103056

9. Yamada K, Zoarski GH, Rothman MI, Zagardo MT, Nishimura T, Sun CCJ. An intracranial aspergilloma with low signal on T2-weighted images corresponding to iron accumulation. Neuroradiology. 2001;43:559-61. http://dx.doi.org/10.1007/ s002340000535

10. Stodulski D, Kowalska B, Stankiewicz C. Otogenic skull base osteomyelitis caused by invasive fungal infection. Eur Arch Otorhinolaryngol. 2006;263:1070-6. http://dx.doi.org/10.1007/ s00405-006-0118-7

Address for correspondence: Carole Cassagne, IHU Méditerranée Infection, 19-21 Boulevard Jean Moulin, 13005 Marseille, France; email: carole.cassagne@ap-hm.fr

\section{Epizootic Hemorrhagic Disease in White-Tailed Deer, Canada}

\author{
Samantha E. Allen, Jamie L. Rothenburger, ${ }^{1}$ \\ Claire M. Jardine, Aruna Ambagala, \\ Kathleen Hooper-McGrevy, Nicole Colucci, \\ Tara Furukawa-Stoffer, Stacey Vigil, Mark Ruder, \\ Nicole M. Nemeth ${ }^{2}$
}

\begin{abstract}
Author affiliations: University of Guelph and Canadian Wildlife Health Cooperative, Guelph, Ontario, Canada (S.E. Allen, J.L. Rothenburger, C.M. Jardine, N.M. Nemeth); Canadian Food Inspection Agency, Winnipeg, Manitoba, Canada (A. Ambagala, K. Hooper-McGrevy); Canadian Food Inspection Agency, Lethbridge, Alberta, Canada (N. Colucci, T. Furukawa-Stoffer); University of Georgia, Athens, Georgia, USA (S. Vigil, M. Ruder, N.M. Nemeth)
\end{abstract}

DOI: https://doi.org/10.3201/eid2504.180743

Epizootic hemorrhagic disease affects wild and domestic ruminants and has recently spread northward within the United States. In September 2017, we detected epizootic hemorrhagic disease virus in wild white-tailed deer, Odocoileus virginianus, in east-central Canada. Culicoides spp. midges of the subgenus Avaritia were the most common potential vectors identified on site.

$\mathrm{E}$ pizootic hemorrhagic disease viruses (EHDVs) and bluetongue viruses (BTVs) are Culicoides spp. midgetransmitted orbiviruses that represent an imminent threat to the health of ruminant livestock and wildlife. For susceptible ruminants, EHDV and BTV infections can result in high rates of illness and death, leading to severe economic hardship to the agricultural sector (1). These viruses have a historical geographic range of $40^{\circ} \mathrm{N}-50^{\circ} \mathrm{N}$ and $35^{\circ} \mathrm{S}$, following the distribution of the Culicoides vectors. However, the epidemiology of these pathogens is changing, with decades of northward expansion into areas of Europe and North America with immunologically naive hosts (1-3).

In Canada, EHDV has rarely and sporadically been detected in the southern portions of British Columbia, Alberta, and Saskatchewan (4). We report the detection of EHDV in white-tailed deer, Odocoileus virginianus, in east-central Canada, providing further evidence of the northern range expansion of orbiviruses within North America.

On September 7, 2017, two wild white-tailed deer carcasses were found in a seminatural area adjacent to a

${ }^{1}$ Current affiliation: University of Calgary, Calgary, Alberta, Canada.

${ }^{2}$ Current affiliation: University of Georgia, Athens, Georgia, USA. 